\title{
Knowledge and affective traits of physiotherapy students to provide care for patients living with AIDS.
}

\begin{abstract}
Purpose: This study aimed to assess Nigerian physiotherapy students' knowledge and their affective traits in caring for patients living with AIDS (PWA).

Methods: Nigerian students $(N=104)$ in four training programs were surveyed using a 43-item questionnaire that elicited information on the students' demographics characteristics, knowledge levels on AIDS transmission, universal precaution and pathophysiology, their feeling of preparedness, comfort, ethical disposition for PWA and their willingness to evaluate and provide care to PWA in different clinical scenarios.
\end{abstract}

Results: Overall the students showed unsatisfactory knowledge of universal precaution and AIDS pathophysiology and did not feel comfortable or prepared to care for PWA. The students did not also show satisfactory ethical disposition and may be unwilling to care for PWA. The students' knowledge levels on AIDS transmission and willingness were influenced by religious affiliation while feeling of comfort and ethical disposition were influenced by gender and knowing someone living with AIDS. They were more unwilling to provide whirlpool wound care procedures and chest physiotherapy compared to providing gait training, therapeutic exercise and activities of daily living training for PWA.

Conclusion: The study identified the need to improve the curriculum on AIDS and recommends clinical clerkship and a methodical and sequential exposure of students to cases during clinical rotations.

\section{KEY WORDS: AIDS KNOWLEDGE, AFFECTIVE TRAITS, WILLINGNESS, CLINICAL SCENARIOS.}

\section{Introduction and background}

It is widely known that knowledge of a disease or condition alone without affective traits or attributes may not result in an optimal outcome. By definition, affective traits are characteristics that are influenced by or resulting from emotions (Mariam-Webster dictionary) and factors that could influence acquisition and exhibition of the traits may include cultural beliefs, disease complexities, co-morbidities, signs and symptoms, impairment and functional limitations resulting from a disease, and the nature of the specific interventions involved in managing the disease or condition.

Using search terms including health professionals, nurses, physical therapists, physicians, knowledge, attitude, willingness, disposition, students and AIDS, by language (English), Medline was searched for years 1995-2008. The search turned out many previous studies which showed that students of health professions including nursing, medicine, physiotherapy and occupational therapy have unsatisfactory knowledge of AIDS transmission and pathophysiology (Balogun et al, 1998; Leasure et al, 1996; Held, 1993; Beitz, 1992; Dowd, 1991; Vincent and Schkade, 1990), harbored negative attitude (Mill et al, 2004; Balogun et al, 1998; Leasure et al, 1996; Held, 1993; Beitz, 1992; Dowd, 1991; Vincent and Schkade, 1990), and were unwilling to render care to patients living with AIDS (PWA) (Mill et al, 2004; Balogun et al, 1998; Currey et al, 1990).

Reports on physiotherapy students is limited to two studies from the US (Balogun et al, 1998; Leasure et al, 1996), and one each from Australia (Gilchrist et al, 1997), United Kingdom (Johnson and Sim, 1998), and South Africa (Puckree et al, 2004). Johnson and Sims (1998) found satisfactory knowledge, positive attitude and positive association between knowledge and attitudes among physiotherapy students, while the other studies reported below satisfactory knowledge, poor attitudes and unwillingness to provide care to PWA among physiotherapy students (Puckree et al, 2004; Balogun et al, 1998; Gilchrist et al, 1997; Leasure et al, 1996). South African students did not feel adequately prepared to care for PWA, only $45 \%$ of them identified a used hypodermic needle as a source of infection, 37\% knew HIV could be transmitted from mother to child and 15\%
Correspondence to:
Adewale L. Oyeyemi,
MSc Lecturer
Department of Physiotherapy
College of Medical Sciences
University of Maiduguri
Nigeria.
E-mail: alaoyeyemi@yahoo.com 
knew the protocol to be followed if they were exposed to an infected person's body fluids (Puckree et al, 2004).

Physiotherapy students in Australia believed they are at risk when PWA sneezes or coughs $(31 \%)$, when they come in contact with AIDS survivors' non-blood tinged sputum (35\%), when they perform sputum induction on them $(82 \%)$ and when they share eating utensils with them (31\%) (Gilchrist et al, 1997). While most Australian students $(71 \%)$ would be willing to care for PWA, only $44 \%$ would be comfortable doing so and $42 \%$ believed treating these patients will endanger their health. Positive association was found between willingness and knowledge of transmission among Australian physiotherapy students (Gilchrit et al 1997). In India, female medical students showed better attitude to PWA than their male counterparts (Samant et al, 2006). Older nursing students showed more positive attitude to AIDS survivors than their younger counterparts in an area of high AIDS incidence in one US city (Cornelius, 2006).

The literature revealed two studies that assessed physiotherapy students' global knowledge, attitude and willingness to care for PWA (Balogun et al, 1998; Held, 1993), one that assessed knowledge on etiology and epidemiology, and also assessed students' attitude (Jonson and Sim, 1998) and another that assessed knowledge of HIV transmission, infection control procedure, willingness, and ethical disposition among physiotherapy students (Gilchrist et al, 1997). A multicentered study assessed South African physiotherapy students' knowledge of HIV/AIDS treatment approaches, attitude, and preparedness (Puckree et al, 2004). No study that assessed students' responses in different clinical scenarios involving PWA was found.

In the present study, affective traits is used to qualify attributes such as positive ethical disposition, willingness, feeling of comfort, and preparedness in providing care for PWA. Ethical disposition is operationally defined as the degree to which a person identifies with or conform to the accepted principle of right or wrong as it relates to a decision to provide care to patients. A caregiver with positive ethical disposition subordinates self interest and personal preferences to the ethical duty and obligation to provide care regardless of the status of the care recipients or the condition. The purpose of this study was to assess Nigerian physiotherapy students' knowledge levels on AIDS transmission, universal precaution and pathophysiology. It was also to assess the students' preparedness, level of comfort, ethical disposition and their willingness to evaluate and care for PWA in different clinical scenarios.

\section{Materials and methods}

\section{Sample}

A purposive sample of Nigerian physiotherapy students $(\mathrm{N}=104)$ from the University of Nigeria (UNN), Bayero University (BUK), Obafemi Awolowo University (OAU) and University of Ibadan (UIB) in the last two years of their training were surveyed. Of the 110 surveys distributed, 104 usable responses were received, giving a response rate of $94.6 \%$.

\section{Instrument}

A two-part 46-item questionnaire was utilized. All items were obtained from a previously developed instrument with permission from the originating author (Balogun et al, 1998). The final instrument was validated by six experts comprising two physicians, two physiotherapists and two behavioral scientists, each of more than 10 years post qualification experience in their fields. Following the administration of the questionnaire to 10 physiotherapists within a 2-week interval, correlation coefficient of the subscales ranged between 0.72 to 0.88 , indicating moderate reproducibility of the subscales and also establishing their summative values.

Part one elicited sociodemographic information, information on previous experience with PWA and previous AIDS educational instructions. Students were asked whether they knew any family member or another person with AIDS, ever provided services to PWA and whether they ever refused to provide care to PWA. The responses were either "Yes" or "No". Part two of the ques- tionnaire comprised three subscales that evaluated knowledge of transmission, precaution and pathophysiology of HIV/ AIDS. Three attitude subscales assessing comfort, preparedness and ethical disposition, and one subscale on willingness to evaluate and provide intervention in five clinical scenarios involving PWA. The knowledge subscale comprises eight questions on AIDS transmission, six questions on pathophysiology and four questions on universal precautions. The questions were framed to elicit "Yes", "No" or "Not sure" responses. Only the correct answers were counted and "Not Sure' responses were not given any credit. A high score indicates good knowledge on each of the components.

The attitude subscales elicited respondents' feeling of preparedness (4 questions), comfort (5 questions) and ethical disposition (4 questions) in caring for PWA. Responses were rated on a five-point Likert scale ranging from strongly agree (1) to strongly disagree (5). The maximum scores were 20, 25 and 20 for preparedness, comfort, and ethical disposition subscales respectively. Questions on these subscales were worded negatively, therefore the higher the subjects' total score, the better their feeling of preparedness, comfort and ethical disposition.

The willingness subscale consisted of five clinical scenarios in which subject rated their willingness to evaluate and provide intervention to PWA (identified by fictitious names). One clinical scenario involved a patient named Frank with a diagnosis of AIDS and pneumocystis carinii pneumonia and who was referred for bedside chest physiotherapy consisting of postural drainage, percussion and vibration, and breathing and coughing exercises. Respondents were asked if they would be willing to evaluate and treat in each clinical scenarios on a five-point Likert scale ranging from strongly willing (1) to strongly unwilling (5). All five items on the subscale were worded positively to minimize the inherent contamination and response shift bias due to social desirability phenomenon (Anastasi, 1982). The minimum and maximum score for this subscale are 5 and 25, respectively and the higher the subjects 
Table 1: Students' demographic characteristics and previous experience and encounters with persons living with AIDS ( $N=104)$

\begin{tabular}{|l|l|l|l|}
\hline Independent Variable & $\mathbf{n}$ & $\%$ & $\begin{array}{l}\text { Chi } \\
\text { Statistics }\end{array}$ \\
\hline Clinical Year: & & & \\
\hline One & 41 & 39.4 & \\
\hline Two & 63 & 60.6 & $13.46^{*}$ \\
\hline Religion: & & & \\
\hline Christianity & 69 & 66.3 & \\
\hline Islam & 35 & 33.7 & $58.76^{*}$ \\
\hline $\begin{array}{l}\text { Ever been asked to provide } \\
\text { services for PWA: }\end{array}$ & & & \\
\hline Yes & 29 & 27.9 & \\
\hline No & 75 & 72.1 & $15.20^{\star}$ \\
\hline $\begin{array}{l}\text { Ever refused to provide } \\
\text { service to PWA: }\end{array}$ & & & \\
\hline Yes & 4 & 3.8 & \\
\hline No & 100 & 96.2 & 7.31 \\
\hline Ever cared for PWA: & & & \\
\hline Yes & 37 & 35.2 & 12.27 \\
\hline No & 66 & 62.9 & \\
\hline Know someone living with AIDS: & & & \\
\hline Yes & 48 & 46.2 & 4.40 \\
\hline No & 56 & 53.8 & \\
\hline Will care for PWA if asked: & & & \\
\hline Yes & 69 & 66.3 & \\
\hline No & 35 & 33.6 & \\
\hline $\begin{array}{l}\text { Ever received instructions on } \\
\text { HIV/AIDS: }\end{array}$ & & & \\
\hline Yes & 78 & 75.0 & \\
\hline No & 26 & 25.0 & \\
\hline $\begin{array}{l}\text { Satisfied with instructions on } \\
\text { HIV/AIDS: }\end{array}$ & & & \\
\hline Yes & & & \\
\hline No & & & \\
\hline
\end{tabular}

*Indicates significant group differences in the observed proportions for the indicated variable

^Subtotals on 'satisfied with instructions on HIV/AIDS' do not add up to 104 because this question does not apply to those who have not received instructions on AIDS.

total score, the less the willingness to provide service for PWA.

For the knowledge subscale, 75\% correct score on transmission (6 out of 8) and universal precaution (3 of 4) were considered satisfactory, while
Satisfactory score on preparedness and ethical disposition was $75 \%$ positive (3 of 4 ), while $80 \%$ positive response was considered satisfactory (4 of 5) on comfort. The threshold of $75 \%$ to $80 \%$ was selected based on a description of satisfactory responses in a previous study (Balogun et al, 1998).

The questionnaires were distributed to the subjects by research workers in each centers following scheduled lectures on topics unrelated to AIDS. A cover letter assures anonymity and that completion of the questionnaires implied consent. Ethical approval was sought and obtained from the principal author's institution.

\section{Data Analysis}

Using Analyse-It Statistical Software (Analyze-It Ltd, Leeds, United Kingdom), descriptive statistics was computed and analysis of variance (ANOVA) was used to determine the influence of sociodemographic variables on knowledge and affective traits. Proportional differences were explored using chi statistics and Wilcoxon's signed ranked test was utilized to assess differences in willingness in the clinical scenarios. Differences were considered significant at an alpha level of 0.05 .

\section{Results}

The students age ranged between 19 and 35 (mean=24.5, $\mathrm{SD}=2.7$ ). Majority $(60.7 \%)$ were male, $11.5 \%$ were married. Audiovisuals, lecture, clinical observation, group discussion and selected reading were reported to be the most effective mode of instruction by $34.6 \%, 32.3 \%, 17.3 \%, 13.5 \%$ and $2.3 \%$ of the subjects respectively. As shown in Table 1, majority of the students $(66.3 \%)$ identified themselves as Christians and $53.8 \%$ did not know anyone living with AIDS. Most (72.1\%) had not previously been asked to provide care to PWA, $62.9 \%$ had experience in caring for PWA, and $75.0 \%$ had received instructions on HIV/AIDS. The students were satisfied $(29.0 \%)$, somewhat satisfied $(37.5 \%)$ or were not satisfied (17.9\%) with the instructions received. Students in BUK and UNN programs tend to have been asked to care for PWA more frequently than UIB or OAU groups (chi statistic = 15.2, $\mathrm{p}<0.02$ ). While the UNN students 
tend to indicate that they have received AIDS instructions, the BUK students tend to indicate that they have not received AIDS instructions than other groups (chi statistics $=20.7, \mathrm{p}<0.01$ )

The mean knowledge score of the subjects were 5.7 $(\mathrm{SD}=1.2), 2.1(\mathrm{SD}=1.1)$ and $2.9(\mathrm{SD}=1.2)$ for transmission, precaution and pathophysiology respectively, indicating overall unsatisfactory scores on knowledge of transmission, precaution and pathophysiology. As shown in Table 2 while $64 \%$ of the students gave $75 \%$ correct response (satisfactory score) on transmission, only $32.7 \%$ scored to the satisfactory level on pathophysiology. The mean score on attitudes components are $16.5(\mathrm{SD}=4.5)$, $14.1(\mathrm{SD}=3.2)$ and $13.4(\mathrm{SD}=3.5)$ for comfort, ethical disposition and preparedness respectively. Majority of the respondents showed unsatisfactory responses on comfort, ethical disposition and preparedness (64.4\%, 52.9\% and $51.9 \%$ respectively), indicating that overall the students were not comfortable, did not feel prepared and have low positive disposition when it comes to caring for PWA.

The students' mean willingness score is $11.1(\mathrm{SD}=3.3)$ out of a total possible score of 25 , which showed some of the students may be unwilling or at least showed reluctance to provide care for PWA. Table 3 showed the students' willingness to evaluate and treat patients in different patient scenarios. Least willingness (high score) was observed for a patient (named Tim) with decubitus, peripheral sensory neuropathy and pain, referred for assessment and treatment with whirlpool and transcutaneous electrical nerve stimulation (mean= 2.8, SD=1.3). Highest willingness (least score) was found for a patient (named Joe) with progressive symmetrical paraparesis, weakness, parasthesia, gait difficulties, muscle deterioration and incontinence, referred for therapeutic exercises and activities of daily living and gait training (mean score $=1.9$, $\mathrm{SD}=0.7)$. Willingness was significantly lower $(\mathrm{p}<0.001)$ for patient named Tim compared to a named Matt $($ mean $=2.8$, $\mathrm{SD}=1.3$ vs. $2.3, \mathrm{SD}=1.0$ ).

Students who identified themselves as Christians scored significantly higher

Table 2: Students' scores on knowledge and affective traits components.

\begin{tabular}{|l|l|lc|lc|}
\hline Subscale & Mean (SD) & \multicolumn{2}{|c|}{ Satisfactory } & \multicolumn{2}{|c|}{ Unsatisfactory } \\
$\mathbf{n}$ & & & & \\
Knowledge: & & & & \\
\hline $\begin{array}{l}\text { Knowledge of } \\
\text { Transmission }\end{array}$ & $5.7(1.2)$ & 64 & 40 & 38.5 \\
\hline $\begin{array}{l}\text { Knowledge of } \\
\text { Precaution }\end{array}$ & $2.1(1.1)$ & 34 & 32.7 & 70 & 32.7 \\
\hline $\begin{array}{l}\text { Knowledge of } \\
\text { Pathophysiology }\end{array}$ & $2.9(1.2)$ & 5 & 4.8 & 99 & 95.2 \\
\hline Attitude: & $16.5(4.5)$ & 37 & 35.6 & 67 & 64.4 \\
\hline $\begin{array}{l}\text { Comfort with } \\
\text { care of PWA }\end{array}$ & $14.1(3.2)$ & 49 & 47.1 & 55 & 52.9 \\
\hline $\begin{array}{l}\text { Ethical } \\
\text { Disposition }\end{array}$ & $13.4(3.5)$ & 45 & 43.3 & 9 & 51.9 \\
\hline \begin{tabular}{l} 
Preparedness \\
\hline
\end{tabular}
\end{tabular}

Satisfactory scores are $75 \%$ correct score on transmission and precaution or $80 \%$ score on pathophysiology on knowledge components, or positive response (Disagree or Strongly Disagree) on 75\% (3 of 4) of items on comfort and ethical disposition or $80 \%$ ( 4 of 5) on items on preparedness of the attitude components. Satisfactory score were values based on reports by Balogun et al (1998). J Phys Ther Educ. 2:57-63

The higher the mean score the more knowledgeable, the better the attitude toward persons with AIDS (PWA).

Possible range of scores for Transmission= 0-4, Precaution 0-6, Pathophysiology 0-10; Comfort =5-25, Ethics and Rights $=5-20$; Competence and preparedness $5-20$

than those who identified themselves as Muslims on knowledge of transmission (mean $=5.9, \mathrm{SD}=1.1$ vs. $5.2, \mathrm{SD}=1.3$, $\mathrm{p}<0.01)$ and willingness (mean $=10.2$, $\mathrm{SD}=2.9$ vs. $11.9, \mathrm{SD}=3.3, \mathrm{p}<0.05)$. The OAU group scored significantly higher $(\mathrm{p}<0.05)$ on knowledge of transmission than the BUK group (mean=6.1, $\mathrm{SD}=1.2$ vs. $5.2, \mathrm{SD}=1.3$ ), and male students were more comfortable caring for PWA $(\mathrm{p}<0.01)$ than female students (mean=15.1, $\mathrm{SD}=4.9$ vs. $17.1, \mathrm{SD}=3.9$ ). Those who knew family members or PWA scored significantly higher $(p<0.01)$ on ethical disposition than those who did not (mean=15.1, SD=3.0 vs. 13.2, $\mathrm{SD}=3.2$ ). Those who answered "Yes" to the question "Are you willing to care for PWA if asked" showed better willingness $(p<0.01)$ than those who answered "No" or were undecided. Significant but tenuous correlation was found between feeling of preparedness and ethical disposition $(r=0.29$, $\mathrm{p}<0.003$ ), comfort and willingness $(\mathrm{r}=0.23, \mathrm{p}<0.004)$, age and willingness $(\mathrm{r}=0.23, \mathrm{p}<0.021)$ and young age and preparedness $(\mathrm{r}=0.22, \mathrm{p}<0.032)$.

\section{Discussion}

In Nigeria, after secondary education, physiotherapy students spend three years in the pre-clinical phase and two years in the clinical phase of their professional education, followed by one year internship. During a year long compulsory national service after internship, physiotherapists can be posted to work in hospitals and health centers in rural communities and may be the only rehabilitation professional in their communities.

Knowledge of Transmission, Precaution and Pathophysiology

Overall unsatisfactory knowledge levels on pathophysiology and universal precaution shown by the Nigerian students reflects a general trend among physiotherapy students in several countries 
Table3: Frequencies and mean students rating of their willingness to evaluate and treat patients living with AIDS

\begin{tabular}{|l|l|l|l|l|l|l|}
\hline Patient & SA & AG & ND & DA & SD & Mean \\
\hline Joe $^{1}$ & 32.7 & 46.2 & 20.1 & 1.0 & 0 & $1.9(0.7)^{\mathrm{a}}$ \\
\hline Frank $^{2}$ & 19.2 & 22.1 & 47.1 & 8.7 & 2.8 & $2.5(1.0)^{\mathrm{b}}$ \\
\hline Sarah $^{3}$ & 40.4 & 35.6 & 23.0 & 1.0 & 0 & $1.9(0.8)^{\mathrm{a}}$ \\
\hline Tim $^{4}$ & 17.3 & 18.3 & 39.4 & 18.3 & 6.7 & $2.8(1.3)^{\mathrm{c}}$ \\
\hline Matt $^{5}$ & 20.2 & 37.5 & 35.6 & 2.8 & 2.8 & $2.3(1.0)^{\mathrm{d}}$ \\
\hline
\end{tabular}

$\mathrm{SA}=$ Strongly Agree, $\mathrm{AG}=$ Agree ND=Neither Agree nor Disagree, $\mathrm{DA}=$ Disagree, $\mathrm{SD}=$ Strongly Disagree,

${ }^{1}$ Joe(not real name) is a patient with a diagnosis of AIDS and progressive symmetrical paraparesis. He presents with weakness, parasthesias, gait difficulties, muscle deterioration, and incontinence. Joe has been referred to physiotherapy (PT) for gait and ADL training, and a therapeutic exercise program. I would be willing to evaluate and treat Joe.

${ }^{2}$ Frank (not real name) is a patient with a diagnosis of AIDS and pneumocystis carinii pneumonia. He has been referred for bedside chest PT consisting of postural drainage, percussion and vibration, and breathing and coughing exercises. I would be willing to evaluate and treat Frank for chest PT.

${ }^{3}$ Sarah (not real name) is a 1 year old child with AIDS. She presents with delayed motor development, extreme spasticity, feeding difficulties, and respiratory disease. She has been referred to PT for a program to reduce tone, facilitate normal movement and oral control, and chest care. I would be willing to evaluate and treat Sarah.

${ }^{4} \mathrm{Tim}$ (not real name) is a patient with a diagnosis of AIDS who has been referred to PT for treatment of his skin lesions, decubiti and pain due to peripheral sensory neuropathies. I would be willing to treat Tim with whirlpool and TENS.

${ }^{5}$ Matt (not real name) is a patient with a diagnosis of AIDS and AIDS-Related Dementia. He is currently being cared for at home and presents with hypertonia, personality changes with periods of confusion and agitation, dysarthria, incontinence, and seizure. He has been referred for home physical therapy treatment to reduce tone, improve activities of daily living skills and a general exercise program. I would be willing to evaluate and treat Matt with home physiotherapy.

The lower the mean the better the willingness. Mean with different letter superscript are significantly different $(p<0.01)$ from each other while those with the same superscript are not. For example the level of willingness in the scenario involving Frank is lower than in the scenario involving Joe, but not different from that of Sarah

including United States of America and South Africa (Puckree et al, 2004; Balogun et al, 1998; Held, 1993), a situation found even among qualified physicians and nurses in several countires (Oyeyemi et al, 2006; Quach et al, 2005; Juan et al, 2004; Data and Bandyopadhyay, 1997). The pattern of Nigerian students' inadequate knowledge of AIDS transmission is comparable to those of their Australian counterparts, a quarter to over one-third of whom have inaccurate perception on the risk of cross infection and believe they should wear protective clothing for all interaction with PWA (Gilchrist et al, 1997). Similarly, the disparity in knowledge on transmission between two programs (BUK and OAU) mimics the situation in another study (Puckree et al, 2004), where students in 4 of 7 programs knew of the precaution to take when suctioning HIV infected person.

\section{Comfort Preparedness and Ethical Disposition}

Most students (64.4\%) were not comfortable treating PWA and over a half did not have satisfactory ethical disposition and did not feel prepared to care for PWA. While the low prevalence of satisfactory comfort level among Nigerian students in the present study (35.6\%) approaches those of the Australian students, $44 \%$ of whom were comfortable treating PWA (Gilchrist et al, 1997), the level of prevalence of preparedness among these students $(43.3 \%)$ exceeded those of their South African counterparts, $79 \%$ of whom believed their training did not adequately prepare them to cope with HIV/AIDS patients (Puckree et al, 2004). Prevalence of unsatisfactory ethical disposition among Nigerian students $(47.1 \%)$ lags behind those of their Australian counterparts, $78 \%$ of whom did not belief physiotherapists should lose their job for refusing to care for PWA and only $16 \%$ of whom would administer the life saving procedure of mouth-to-mouth resuscitation to PWA (Gilchrist et al, 1997). Students' unsatisfactory comfort level and ethical disposition may be attributed to fears of contracting HIV, a common trend among health professionals (Peretti-Watel et al, 2004; Owotade et al, 2003; Brachman et al, 1996). It may also be attributed to societal stigma against PWA, as many in Nigeria are believed to hold judgmental views against $\mathrm{PWA}$.

\section{Willingness in Clinical Scenarios}

The scenario of skin lesion, decubitus and pain and treatment including whirlpool and transcutaneous electrical stimulation provoked lower willingness among Nigerian physiotherapy students than others scenarios. Overall, findings on clinical scenarios suggest that the students may be less willing to provide wound care and chest physiotherapy than exercises and ADL and gait training for PWA, except if the survivor is a child. The scenario involving a child may have attracted better willingness compared to three other scenarios including the one with similar treatment that include chest physiotherapy, because the students perhaps viewed a child as helpless and deserving of empathy more than adults in any situation. Furthermore, while adult may be erroneously presumed to be deserving of blame for contracting HIV through promiscuous sexual behavior, 
a child could be viewed as innocent.

Nigerian physiotherapy students' response on willingness to provide care to PWA should be interpreted with caution because responses indicating lack of willingness may not be explained by fears of contracting HIV infection alone. For example in the scenarios involving patient with pneumocystis carinii pneumonia, the students may be unwilling to provide postural drainage, percussion and vibration if they perceive the pneumonia as of interstitial type in which physiotherapy may not be of any benefit (Britton et al, 1985). A discrepancy between the students' response that they would provide care if asked and overall low willingness score showed that the students may face ethical dilemma when it comes to caring for PWA. It is plausible that these students would adhere to the ethical principle of beneficence or the duty to treat in theory, but may show reluctance when directly confronted with situations as depicted in the clinical scenarios.

\section{Educational Implications of our findings}

Finding of inadequate knowledge of precaution and AIDS pathophysiology shows that the necessary skill in the cognitive domain to render care to PWA has not been acquired by students in this study. By not feeling comfortable and prepared and by showing low ethical disposition overall, it would seem that the affective traits needed to provide care for PWA have not been cultivated by most of the students towards the end of their training. Lower willingness in the scenarios involving pulmonary toileting and wound care indicates that PWA with pulmonary conditions and skin ulcers could face discrimination in their care and may even be denied necessary care if students graduate without being prepared to face challenges in managing patient with known and unknown HIV status.

Therefore in addition to clinical clerkship on HIV/AIDS, a methodical and sequential clinical exposure is recommended to facilitate students acquisitions of the skills needed to manage AIDS. Potential influence of gender and religious affiliation and possible celebrity participation should be considered in any educational program- ming. Future study to compare students' response on PWA and patients infected with hepatitis B virus, a contagious condition with similar transmission pattern as HIV is suggested to elucidate the stigma attached to AIDS.

\section{Conclusion}

Physiotherapy students in Nigeria showed unsatisfactory knowledge of universal precaution and AIDS pathophysiology, did not feel comfortable or prepared and showed low ethical disposition when it comes to caring for PWA. The students were more unwilling to provide care to PWA with open wounds or pulmonary conditions than to care for patients with musculoskeletal or neurological impairments. The study found influence of religious affiliation on knowledge of transmission and willingness, gender influence on comfort and knowing someone with AIDS on ethical disposition among students. It also found links between age and students' willingness and preparedness.

\section{References}

Anastasi A 1982 Psychological Testing. $5^{\text {th }}$ ed. New York, NY: Macmillan Publishing Co.

Balogun JA, Kaplan MT, Hoeberlein-Miller T, Anthony A, Lefkowitz R, Hsia L 1998 Knowledge, attitudes, and willingness of junior health care professional Students to provide services for patients with acquired immunodeficiency syndrome. Journal of Physical Therapy Education 2:57-63

Beitz JM 1992 A survey of allied health students' knowledge of HIV and AIDS. Today's OR Nurse (Today's Surgical Nurse) 14(5): 16-23

Brachman P, Karzarsky P, Cetron M, Jacob MS, Boonit B et al. 1996 Knowledge and attitude of hospital -based physicians and trainees about HIV Infection in the United States, Canada, India, and Thailand. Archives of Internal Medicine 156: 761-766

Britton S, Bejstedt M, Vedin L 1985 Chest physiotherapy in primary pneumonia. British Medical Journal 290: 1703-4

Cornelius JB 2006 HIV- related knowledge, attitudes and perceived risk of exposure of AfricanAmerican Nursing students from a high prevalence AIDS area. Journal of Multicultural Nursing and Health 12 (1):41-50

Currey CJ, Johnson M, Ogden B 1990 Willingness of health professions students to treat patients with AIDS. Academic Medicine. 65:472-474

Data C, Bandyopadhyay D 1997 Knowledge and attitude in relation to HIV/AIDS among in-service nurses of Calcutta. Journal of Indian Medical Association. 95:75-7
Dowd SB 1991 The knowledge and attitudes of radiologic technologists and allied health students regarding AIDS. Canadian Journal of Medical Radiology Technology 22(1):19-22

Gilchrist H, Sullivan G, Heard R 1997 Attitudes of Australian physiotherapy students towards AIDS. Physiotherapy Theory and Practice 13 (4): 265-78.

Held SL 1993 The effects of an AIDS education program on the knowledge and attitudes of a physical therapy class. Physical Therapy 73:156-164

Johnson C, Sim J 1998 AIDS and HIV: A comparative study of therapy students' knowledge and attitudes. Physiotherapy 84 (1): 37-46.

Juan C, Siebers R, Wu FF, Wu CJ, Chang YJ, Chao C 2004 The attitudes, concerns, gloving practices and knowledge of nurses in a Taiwanese hospital regarding AIDS and HIV. International Journal of Nursing Practice 10 (1): 32-8

Leasure R, Hawkins LA, Merrial A 1996 Stigma: baccalaureate nursing students attitudes towards persons living with AIDS. Journal of Nursing Education 35:234-236 Massachusetts.

Meriam-Webster's Collegiate Dictionary (eleventh edition) 2006. Springfield

Mill JE, Opare M, Fleming DS 2004 Ghanaian nursing students' knowledge and attitudes about HIV illness. African Journal of Nursing and Midwives 6(2): 5-12.

Owotade PJ, Ogunbodede EO, Sowande OA 2003 HIV/AIDS pandemic and surgical practice in a Nigerian teaching hospital. Tropical Doctor 33(4): 228-31.

Oyeyemi A, Oyeyemi B, Bello I 2006 Caring for patients living with AIDS: knowledge, attitude and global level of comfort. Journal of Advance Nursing 53 (2): 196-204

Peretti-Watel P, Bendiane MK, Galinier A, Lapiana JM, Pegliasco H, Obadia Y 2004 Opinion toward pain management and palliative care: comparison between HIV specialists and oncologists. AIDS Care 16(5): 619-27

Puckree T, Chetty BJ, Govender V, Ramparsad S, Lin J 2004 Are physiotherapy graduates adequately prepared to manage HIV/AIDS patients? South African Journal of Physiotherapy 60 (2): 7-10

Quach L, Mayer K, McGarvey ST, Lurie MN, Do P 2005 Knowledge, attitudes, and practices among physicians on HIV/AIDS in Quang Ninh, Vietnam. AIDS Patients Care and STDs 19 (5) 335-46

Samant Y, Mankeshwar R, Sankhe L, Parker DL 2006 HIV - related knowledge and attitudes among first year medical students in Mumbai, India. International Electronic Journal of Health Education 9:13-24

Vincent TA, Schkade JK 1990 Knowledge and attitude of occupational therapy students regarding AIDS. American Journal of Occupational Therapy 44: $205-210$ 